\title{
Molecular structure of a novel cholesterol-responsive A subclass ABC transporter, ABCA9
}

\author{
Armin Piehler, ${ }^{1}$ Wolfgang E. Kaminski, ${ }^{1}$ Jürgen J. Wenzel, Thomas Langmann, \\ and Gerd Schmitz*
}

Institute for Clinical Chemistry and Laboratory Medicine, University of Regensburg, Franz-Josef-Strauß-Allee 11, D-93042, Regensburg, Germany

Received 25 May 2002

\begin{abstract}
We recently identified a novel $\mathrm{ABC}$ A subclass transporter, $\mathrm{ABCA6}$, in human macrophages. Here, we report the molecular cloning of an additional ABC A subfamily transporter from macrophages denoted ABCA9. The identified coding sequence is $4.9 \mathrm{~kb}$ in size and codes for a 1624 amino acid protein product. In accordance with the proposed nomenclature, the novel transporter was designated $\mathrm{ABCA}$. The putative full-length $\mathrm{ABC}$ transporter polypeptide consists of two transmembrane domains and two nucleotide binding folds and thus conforms to the group of full-size $\mathrm{ABC}$ transporters. We identified alternative ABCA9 mRNA variants in human macrophages that predict the existence of three truncated forms of the novel transporter. Among the human $\mathrm{ABC}$ A subfamily transporters, ABCA9 exhibits the highest amino acid sequence homology with ABCA8 (72\%) and ABCA6 (60\%), respectively. The striking amino acid sequence similarity between these transporter molecules supports the notion that they represent an evolutionary more recently emerged subgroup within the family of ABC A transporters, which we refer to as "ABCA6-like transporters." ABCA9 mRNA is ubiquitously expressed with the highest mRNA levels in heart, brain, and fetal tissues. Analysis of the genomic structure revealed that the ABCA9 gene consists of 39 exons that are located within a genomic region of $\sim 85 \mathrm{~kb}$ size on chromosome 17q24.2. In human macrophages, ABCA9 mRNA is induced during monocyte differentiation into macrophages and suppressed by cholesterol import indicating that ABCA9, like other known ABC A subfamily transporters, is a cholesterol-responsive gene. Based on this information, ABCA9 is likely involved in monocyte differentiation and macrophage lipid homeostasis. () 2002 Elsevier Science (USA). All rights reserved.
\end{abstract}

ATP-binding cassette $(\mathrm{ABC})$ transporters constitute a complex group of structurally related multispan transmembrane proteins that mediate the translocation of a broad spectrum of substrates across cellular membranes. These include ions, peptides, sugars, vitamins, and steroid hormones [1,2]. The subgroup of full-size $\mathrm{ABC}$ transporters is structurally characterized by two nucleotide binding folds (NBF) with conserved Walker A and $\mathrm{B}$ motifs, signature sequences, and two transmembrane domains, each typically composed of six membranespanning segments [3]. The specificity for the transported substrates is thought to be determined by the transmembrane domains, whereas the energy required for the transmembrane transport is provided by hydro-

\footnotetext{
${ }^{*}$ Corresponding author. Fax: +49-941-944-6202.

E-mail address: gerd.schmitz@klinik.uni-regensburg.de (G. Schmitz).

${ }^{1}$ These authors contributed equally to this study.
}

lysis of ATP at the two NBF [4]. In the past, some ABC transporters have been studied extensively based on the observation that they are capable of mediating multidrug resistance in cancer therapy.

In the recent years, evidence has accumulated to suggest that $\mathrm{ABC}$ transporters serve important physiological functions in the cellular transmembrane transport of endogenous lipid substrates [5,6]. This concept has been supported by work from our laboratory and others providing evidence that $\mathrm{ABCA} 1$, the prototypic member of the $\mathrm{ABC}$ A subfamily [2], is a major regulator of HDL in the circulation which functions as a facilitator of cellular phospholipid and cholesterol export [7-10]. Interestingly, leukocyte ABCA1 has been shown to directly control the recruitment of macrophages into tissues and the progression of lesions of atherosclerosis [11]. Beside ABCA1, the half-size transporter ABCG1 has been implicated in macrophage cholesterol and phospholipid export [12]. The recent 
finding that mutations in the half-size transporters ABCG5 and ABCG8 cause $\beta$-sitosterolemia, a rare autosomal recessive disorder which is characterized by hyperabsorption of sterols, hypercholesterolemia, decreased biliary excretion of dietary sterols, and premature coronary atherosclerosis [13], has demonstrated a role for $\mathrm{ABC}$ transporters in intestinal sterol uptake $[14,15]$.

We have recently cloned additional members of the ABC A-subclass of transporters from human macrophages [16-18]. Among these, ABCA7 and ABCA2 exhibit significant homology with the phospholipid and cholesterol export facilitator ABCA1. ABCA7 is strongly expressed in tissues that are rich in macrophages and lymphocytes including bone marrow, thymus, spleen, and peripheral blood [16]. In contrast, ABCA2 shows the highest expression in neurologic tissues [19]. The observation that $\mathrm{ABCA} 2$ and $\mathrm{ABCA} 7$ are co-regulated with ABCA1 in response to cholesterol uptake and efflux $[16,17,20]$ suggests roles for these transporters in macrophage lipid trafficking. In a recent study, we identified an additional member of the ABC A-subfamily, designated ABCA6, which is upregulated during monocyte differentiation into human macrophages [18]. However, unlike ABCA1, ABCA2, and ABCA7, the expression of this novel transporter is suppressed during cholesterol uptake of macrophages [12].

In the present study, we report the complete coding sequence and genomic structure of the human ABCA9 gene. We demonstrate that the molecular structure of ABCA9 is highly similar to those of ABCA8 and ABCA6, respectively, and provide evidence for sterol-dependent regulation of ABCA9 in human macrophages.

\section{Materials and methods}

Cell culture and preparation of enzymatically degraded, nonoxidized $L D L$. Human monocytes were obtained from healthy donors by leukapheresis and counterflow elutriation [12]. Aliquots of $10^{8}$ cells were cultured on plastic petri dishes in macrophage SFM medium (Gibco BRL, Karlsruhe) and allowed to differentiate into macrophages for four days in the presence of $50 \mathrm{ng} / \mathrm{ml}$ recombinant human M-CSF (R\&D Systems, Wiesbaden) [12]. Macrophages were incubated in the presence of enzymatically modified LDL (eLDL, $40 \mu \mathrm{g} / \mathrm{ml}$ ) to induce sterol loading for an additional $24 \mathrm{~h}$. LDLs $(d=1.006-1.063 \mathrm{~g} / \mathrm{ml})$ were purified from human plasma obtained from healthy volunteers according to published standard protocols [12]. The preparation was performed in a Beckman L-70 ultracentrifuge (70 Ti rotor) at $4{ }^{\circ} \mathrm{C}$ and densities were adjusted with solid $\mathrm{KBr}$. Lipoprotein fractions were dialyzed repeatedly in phosphate-buffered saline (PBS) containing $5 \mathrm{mM}$ EDTA. After the final dialysis step $(0.15 \mathrm{M} \mathrm{NaCl})$, LDL lipoproteins were sterilized using a $0.45 \mu \mathrm{m}$ sterile filter (Sartorius, Göttingen). Enzymatically degraded, nonoxidized LDL (eLDL) was prepared according to the protocol by Bhakdi et al. [21].

Nucleic acid purification. Total cellular RNA was isolated from monocytes/macrophages by guanidium isothiocyanate lysis and $\mathrm{CsCl}$ centrifugation [22] and RNA was quantitated spectrophotometrically. For preparation of genomic DNA, leukocytes were prepared from $50 \mathrm{ml}$ human venous blood (anti-coagulated with EDTA) by centrif- ugation at $400 \mathrm{~g}$. Genomic DNA was extracted from whole cells using the Qiamp DNA Blood Midi Kit (Qiagen, Hilden).

Cloning of human ABCA9 full-length cDNA. Total RNA from human mononuclear phagocytes that were allowed to differentiate for four days [12] was prepared and aliquots of $1 \mu \mathrm{g}$ were reverse-transcribed in a $20 \mu \mathrm{l}$ RT reaction using the first Strand cDNA Synthesis Kit for RT-PCR (AMV) (Roche, Mannheim). cDNA was amplified in a $50 \mu \mathrm{l}$ reaction volume using the Taq PCR Core Kit (Qiagen, Hilden) (cycle profile: $94{ }^{\circ} \mathrm{C}$ for $20 \mathrm{~s}, 52-62^{\circ} \mathrm{C}$ for $45 \mathrm{~s}$, and $72^{\circ} \mathrm{C}$ for $2-3 \mathrm{~min}$ ). ABCA9-specific PCR segments were amplified utilizing sets of degenerated primers homologous to areas with high similarity between the coding regions of ABCA6 and ABCA8, respectively. The sequences of multiple PCR products contained unique open reading frames and displayed high overall homology with human ABCA8 and ABCA6, respectively. Using primers specific for the identified sequence fragments, the missing interspersed segments were amplified. The assembled overlapping amplification products contained an open reading frame which represented the complete coding region of a novel ABC A-subclass transporter. The flanking ends of the thus identified cDNA were PCR cloned using degenerated primers from regions of maximum homology between ABCA8 and ABCA6. All amplification reactions were sequenced at least in triplicate.

Amplification primers which resulted in the identification of alternative mRNA splice variants were $5^{\prime}$-ATGAAGAACAATCATGG GGTGGCCT-3' (forward), 5'-AGACCATCACAAAACCAGTCAG GACGA-3' (reverse) (ABCA9 $\Delta+55$ ), and $5^{\prime}$-GGTCTCAGGAAAGG GGACGCAATGA-3' (forward), 5'-CAAATGCATTTTGTACCACC TCTGA-3' (reverse) (ABCA9 $\Delta+73$, ABCA9 $\Delta-95)$, respectively.

Semiquantitative $R T-P C R$. Semiquantitative RT-PCR was performed as previously published [12]. For this, the ABCA9-specific primers were used (5'-ATGAAGAACAATCATGGGGTGGCCT-3', forward; 5'-AGACCATCACAAAACCAGTCAGGACGA-3' ${ }^{\prime}$, reverse) yielding a diagnostic fragment of 607 and $662 \mathrm{bp}$, respectively, representing the alternatively spliced $\mathrm{ABCA} 9 \Delta+55$ transcript size. Equal amounts of input RNA were reverse-transcribed and amplified for 25,30 , and 35 cycles, respectively, to monitor that the PCR was in the exponential phase. Amplification of the housekeeping gene GAPDH served to normalize input RNA amounts (not shown) [17].

PCR amplification of intron sequences. PCR cloning of intron sequences was performed using the Taq PCR Core Kit (Qiagen, Hilden) and putative exon-specific oligonucleotide primers for ABCA9 based on gene structure information of ABCA6 [18]. One hundred to five hundred nanogram aliquots of genomic DNA were amplified in a $50 \mu \mathrm{l}$ reaction volume. The reaction mix was composed of $500 \mathrm{nM}$ oligonucleotide primers, $1.5-3 \mathrm{mM} \mathrm{MgCl}_{2}, 200 \mu \mathrm{M}$ dNTP, $10 \times$ Qiagen PCR buffer, and 2 units Taq DNA polymerase (Qiagen, Hilden). After a 2 min denaturation step $\left(94^{\circ} \mathrm{C}\right)$, reaction mixtures were PCR amplified for 40 cycles using the following cycle profile: $94^{\circ} \mathrm{C}$ for $20 \mathrm{~s}, 60$ $65^{\circ} \mathrm{C}$ for $45 \mathrm{~s}$, and $72{ }^{\circ} \mathrm{C}$ for $5 \mathrm{~min}$. Large introns were amplified using the Expand Long Template PCR System (Roche, Mannheim) (according to manufacturer's manual). All PCR amplification products were separated on ethidium bromide stained agarose gels. Bands of interest were excised and the DNA was extracted using the GFX PCR DNA Purification Kit (Amersham, Piescataway) for subsequent sequence analysis.

DNA sequencing. Both strands of GFX purified PCR products were sequenced on an ABI Prism 310 capillary sequencer (PE Applied Biosystems, Weiterstadt) as previously described [16]. Cycle-sequencing reactions were performed with BigDye terminators (DNA Sequencing Kit, PE Applied Biosystems), purified on CentriSep spin columns, and analyzed by capillary electrophoresis.

Analysis of ABCA9 mRNA expression in human tissues. The tissuespecific expression of ABCA9 was characterized using a multiple tissue RNA master blot containing poly $\mathrm{A}^{+}$RNA from various human tissues (Clontech, Heidelberg). A $0.5-\mathrm{kb}$ probe was generated by RTPCR using primers that were derived from a region of minimal homology between $\mathrm{ABCA} 9$, $\mathrm{ABCA} 8$, and ABCA6, respectively. 
The PCR primers used were: $5^{\prime}$-AGCGTGGGTCAGCAAACATG- $3^{\prime}$ (forward) and 5'-TTCTCCCAGAACTCTGAACC-3' (reverse), respectively. For signal detection, the probe was radiolabeled with $\left[\alpha{ }^{32} \mathrm{P}\right] \mathrm{dCTP}$ (Amersham, Freiburg; Oligolabeling Kit, Pharmacia, Freiburg) and hybridization and washing were performed according to published protocols [23]. Subsequently, the tissue blot was quantitated densitometrically and the individual signal densities were translated into a linear integer scale ranging from 0 to 4 ( 0 , no expression; 4 , maximum expression) as described previously $[18,20]$.

Computer sequence analyses. For DNA and protein computer analyses, the WWW ${ }^{2}$ HUSAR GCG software package (DKFZ, Heidelberg) was used. Sequence comparisons and protein alignments were performed using the FASTA and MOTIFS applications, respectively.

\section{Results and discussion}

In this study, we report the identification of the complete cDNA sequence and the characterization of the genomic organization of a novel human $\mathrm{ABC}$ transporter, denoted ABCA9. Moreover, we provide evidence for the existence of multiple alternative ABCA9 transcripts and demonstrate their regulation in response to cholesterol flux in human macrophages.

\section{ABCA9 cDNA and predicted polypeptide structure}

Using an RT-PCR strategy based on large sets of degenerate primers homologous to human ABCA6 and ABCA8 (see Materials and methods), a 4.9-kb transcript containing a 4872-bp open reading frame was amplified from human macrophage cDNA. The detailed sequence has been deposited with the GenBank Database (Accession No. AF423307). The identified open reading frame encodes a 1624 amino acid polypeptide with a calculated molecular weight of approximately $160 \mathrm{kDa}$ (Fig. 1). Nucleotides 4600-4999 (relative to the translation start) of the predicted coding region showed $>99 \%$ homology with a previously reported EST sequence (EST640918), referred to as ABCA9 [24]. Given this observation and in accordance with the currently proposed nomenclature for human $\mathrm{ABC}$ transporters, the novel protein was designated ABCA9. During the preparation of this manuscript, a study came to our attention demonstrating the identification of several ABC transporters on chromosome 17q24 [25]. Among others, a cDNA was reported for ABCA9 that is largely identical with, but at the $5^{\prime}$ end, 45 bp shorter than the ABCA9 mRNA reported here. The ABCA9 molecule predicted by our results contains two NBF with the characteristic Walker $\mathrm{A}$ and $\mathrm{B}$ motifs and a signature sequence is present in the N-terminal NBF (Fig. 1). However, similarly as observed for ABCA6 and $\mathrm{ABCA} 8$, respectively, no genuine signature sequence was identifiable in the C-terminal NBF. The ABCA9 amino acid sequence predicts the existence of two transmembrane domains, each consisting of seven membrane spanning segments. The length of the pre- dicted ABCA9 polypeptide is similar to those observed for ABCA6 (1617 aa) and ABCA8 (1581 aa), respectively, but considerably shorter than that of the other human $\mathrm{ABC}$ A subfamily genes that have as yet been fully characterized. The latter include ABCA1 (2261 aa) [20], ABCA2 (2436 aa) [17], ABCR (2273 aa) [26], and ABCA7 (2146 aa) [16], respectively. Comparison of the predicted $\mathrm{ABCA} 9$ peptide sequence with cloned $\mathrm{ABC}$ full-size transporters revealed strikingly high homologies with human ABCA8 (72\%) and ABCA6 (60\%). In contrast, amino acid identities with other characterized human ABC A subfamily members including ABCA1 (32\%), ABCA2 (32\%), ABCR (31\%), ABCA7 (34\%), and $\mathrm{ABCA} 3(33 \%)$, respectively, were dramatically lower. The observations that the transporters ABCA9, ABCA8, and ABCA6 share extensive amino acid homologies and, at the same time, bear molecular features that clearly set them apart from the other known $\mathrm{ABC} A$ family members strongly support the view that these transporters constitute a distinct $\mathrm{ABC}$ transporter subclass within the $\mathrm{ABC} A$ subfamily. Based on their striking structural similarities and the finding that ABCA9, like ABCA8 and ABCA6, is located on a common genomic locus on chromosome 17q24 (see below), it is likely that all three transporter genes may have evolved from each other by gene duplication or have originated from a common ancestor to form a group of ABCA6-like transporters.

\section{Identification of alternative ABCA9 $\mathrm{mRNA}$ variants in human macrophages}

In the course of the cDNA cloning experiments, we were able to reproducibly amplify an additional band of $0.7 \mathrm{~kb}$ size from macrophage cDNA using primers spanning a segment near the $5^{\prime}$ end of the ABCA9 coding region (base positions 303-910). Moreover, in our efforts to clone the $3^{\prime}$ end of the ABCA9 mRNA, we consistently amplified three distinct bands ranging from 0.7 to $0.9 \mathrm{~kb}$ when primers were used that extended across cDNA positions 4171-4979 (Fig. 2A). Sequencing of the additional $0.7 \mathrm{~kb}$ band obtained from the $5^{\prime}$ end of the coding region revealed that it was specific for ABCA9; however, it contained an additional $55 \mathrm{bp}$ between base positions 800 and 801 of the canonical cDNA sequence ("ABCA9 $\Delta+55$ "). Comparison with the genomic ABCA9 sequence (see below) showed that this site precisely represents the exon 6/exon 7 splice junction in the canonical ABCA9 transcript and that the additional 55-bp segment was completely identical to a sequence located at the $5^{\prime}$ end of intron 6 (Figs. 2B and 4). The ABCA9 $9 \Delta+55$ transcript is thus most likely generated through the partial retention of intron 6 . Sequencing of the two additional bands obtained by PCR amplification of the segment corresponding to base pairs 4171-4979 demonstrated that the $0.8-\mathrm{kb}$ band was 


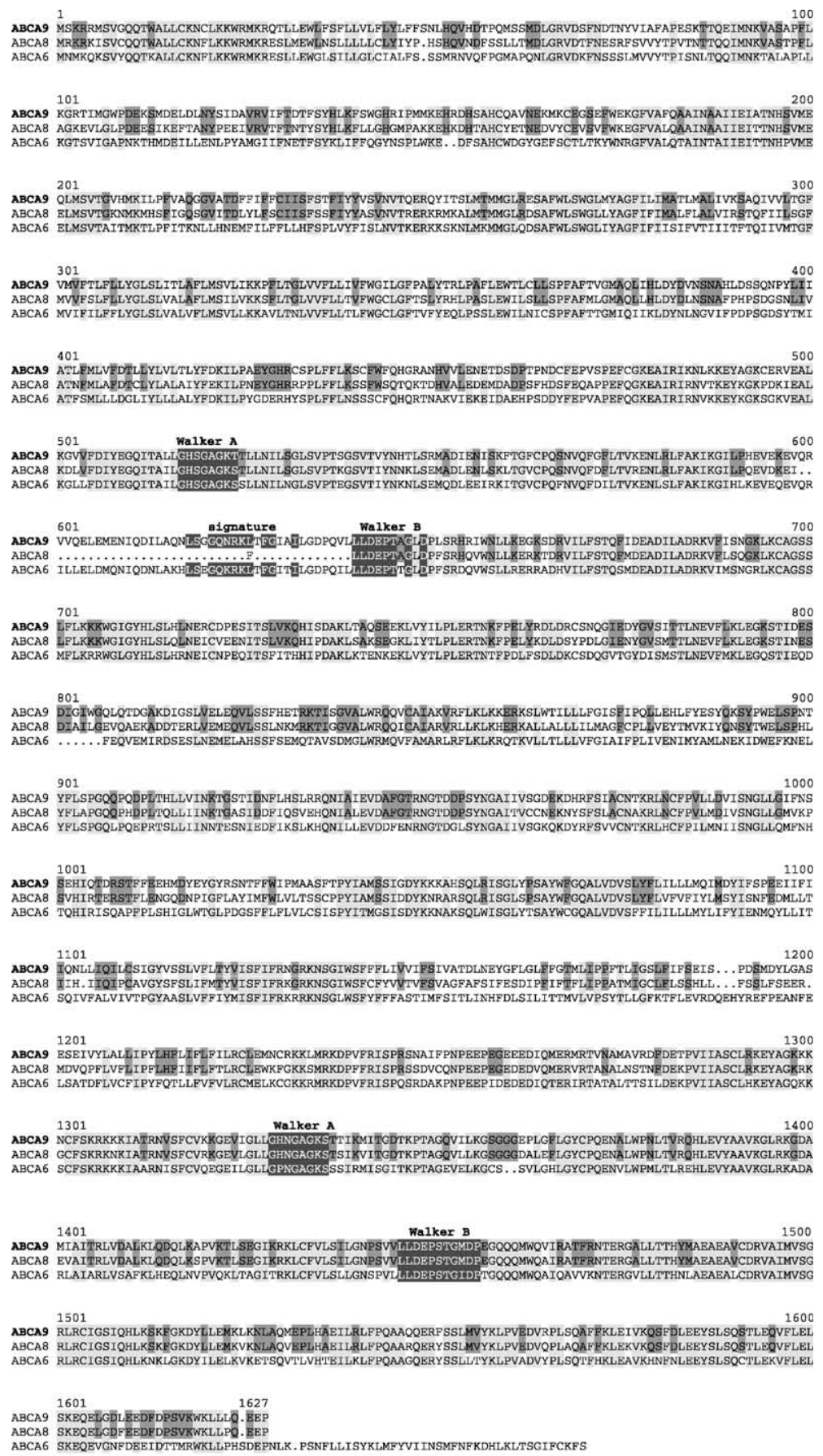

- identity between ABCA9 and ABCA8
identity between ABCA9, ABCA8 and ABCA6, respectively
Walker A, B or signature sequence

Fig. 1. Amino acid sequence of human ABCA9 aligned with its closest homologs ABCA8 and ABCA6, respectively. Amino acids are shown in the single letter code, gaps due to optimal alignment are represented by dots. Annotations designate Walker motifs and the signature sequence of each of the two nucleotide binding domains. Shaded amino acids highlight amino acid identities among ABCA9 and ABCA8 (-.) or all three ABC transporters (--). Canonical Walker A, B motifs and N-terminal signature sequences are indicated (-). The complete ABCA9 cDNA sequence has been deposited with the NCBI-GenBank (Accession No. AF423307).

identical with the canonical ABCA9 cDNA sequence. The $0.9-\mathrm{kb}$ band differed from this sequence in that it contained a 73-bp insertion representing the entire intron 33 ("ABCA9 $\Delta+73$ ") (Fig. 2B). In contrast, we found that the short $0.7 \mathrm{~kb}$ band represented a transcript that completely lacked the $95 \mathrm{bp}$ long exon 34 ("ABCA9 $\Delta-95$ ") (Fig. 2B), strongly suggesting that this transcript is a result of alternative exon skipping.

Interestingly, all three alternative ABCA9 transcripts we found induce frameshifts which ultimately introduce 

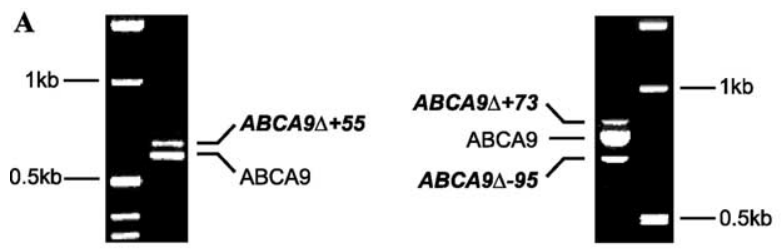

B
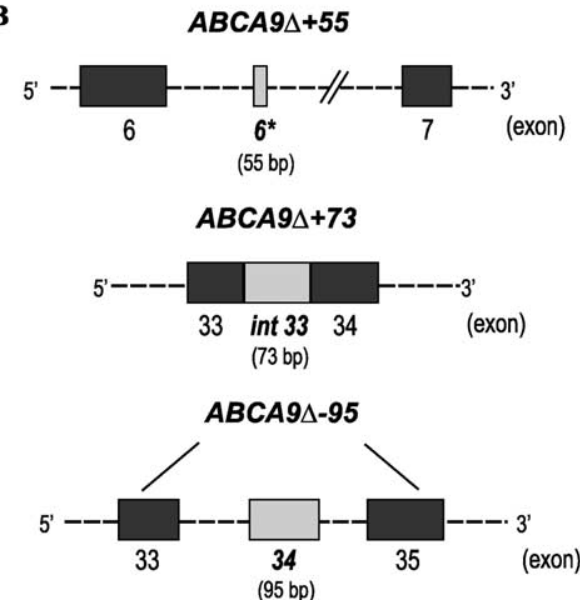

C

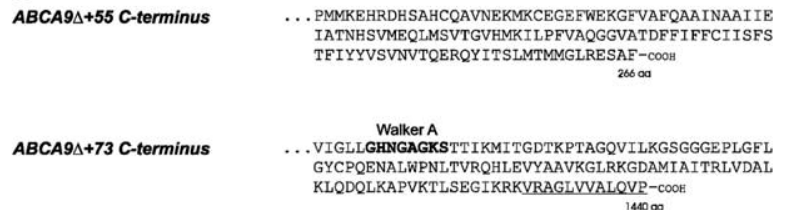

ABCA94-95 C-terminus

Walker A
...VKKKGEVIGLLGMNGAKSTTIKMI TGDTKPTAGQVILKGSGGGE PLGFLGYCPQENALWPNLTVRQHLEVYAAVKGLRKGDAMIAIT LVDALKLQDQLKAPVKTLSEGIKRKAGDSGHL-COOH

D

$A B C A 9 \triangle+55$

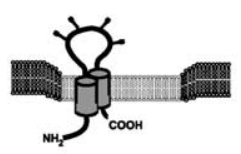

$A B C A 9 \Delta+73$

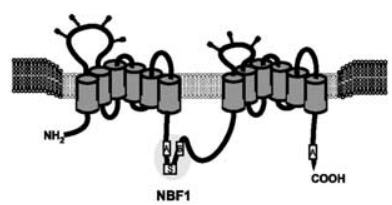

ABCA94-95

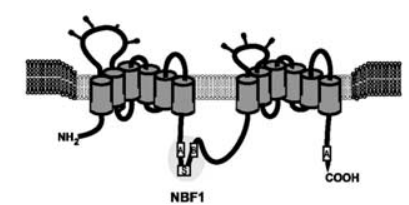

Fig. 2. Alternative ABCA9 mRNA variants in human macrophages. (A) An additional $\sim 0.7 \mathrm{~kb}$ band ("ABCA9 $\Delta+55$ ") was consistently amplified from human macrophage cDNA using primers spanning a 0.6-kb segment (base positions 491-1098) near the $5^{\prime}$ end of the full-length ABCA9 transcript (left). Two additional bands of sizes 0.7 ("ABCA9 $9-95$ ") and $0.9 \mathrm{~kb}$ ("ABCA9 $4+73$ "), respectively, were routinely amplifiable using primers that extend across a $0.8-\mathrm{kb}$ segment at the $3^{\prime}$ end of the canonical ABCA9 mRNA (base positions 4349-5167) (right). Fragment lengths of DNA size marker bands are indicated for orientation. (B) The ABCA9 $\Delta+55 \mathrm{mRNA}$ variant is a result of the alternative retention of a 55-bp subsegment of intron 6 in the coding sequence (exon $6^{*}$ ). The ABCA9 $\Delta+73$ splice variant originates from the complete retention of intron 33 ( $73 \mathrm{bp}$ ), whereas the ABCA9 $\Delta-95$ transcript results from the alternative skipping of the complete exon 34 (95 bp) (see also Fig. 4). (C) C-termini of the truncated polypeptide variants encoded by the alternative ABCA9 mRNAs. Note that the predicted ABCA9 variants ABCA9 +73 and ABCA9 -95 contain incomplete C-terminal nucleotide binding cassettes that are truncated downstream of the respective Walker A motifs (bold face). Newly introduced amino acids due to frameshifts are underlined. Numbers indicate the positions of the respective terminal amino acid. (D) Schematic structure of ABCA9 polypeptide variants predicted by the alternative transcripts ABCA9 $\Delta+55$, ABCA9 $\Delta+73$, and $A B C A 9 \Delta-95$, respectively. A, B, Walker A and B motifs; S, signature sequence; NBF1, nucleotide binding fold 1.

preterminal stops into the coding region. The $\mathrm{ABCA} 9 \Delta+55$, ABCA9 $\Delta+73$, and $\mathrm{ABCA} 9 \Delta-95$ transcripts thus predict the existence of three ABCA9 polypeptide variants of 266,1440 , and 1435 aa size, respectively (Fig. 2C). The function of the alternatively spliced ABCA9 mRNAs is presently unclear. It remains to be established whether they represent regulatory mRNAs or whether they are translated in significant quantities into short ABCA9 polypeptide variants in tissues. Of particular interest in that context is the observation that the ABCA $9 \Delta+73$ and $\mathrm{ABCA} 9 \Delta-95$ transcripts code for truncated ABCA9 polypeptides that contain only one transmembrane domain and the $\mathrm{N}$ terminal NBF (Fig. 2D).

\section{ABCA9 expression in human macrophages is suppressed by cholesterol overload}

In previous studies, we demonstrated that the expression of a significant number of human $\mathrm{ABC}$ transporters in macrophages is regulated during monocyte differentiation into macrophages and by cellular cholesterol transport. Intriguingly, this group of cholesterol-responsive macrophage ABC transporters includes the majority of the cloned ABC A-subfamily members $[12,16,17]$. To test the hypothesis that gene expression of ABCA9 is regulated by sterol, freshly isolated human monocytes were allowed to differentiate into macrophages for four days in the presence of M-CSF and subsequently loaded with enzymatically modified LDL (eLDL) [21] for $24 \mathrm{~h}$ as previously described [17]. We found that the ABCA9 mRNA levels were upregulated during monocyte differentiation into macrophages (Fig. 3). Importantly, loading of macrophages with eLDL strongly reduced the expression of the ABCA9 gene in macrophages (Fig. 3). The induction of ABCA9 expression during M-CSF-dependent monocyte differentiation into macrophages and its suppression in response to sterol influx suggest roles for this transporter in macrophage lineage commitment 


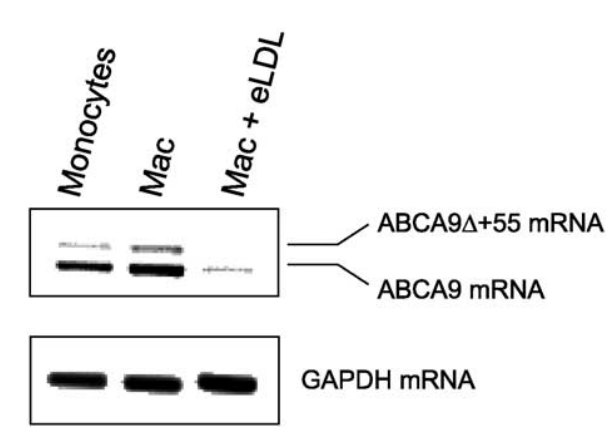

Fig. 3. Downregulation of ABCA9 mRNA in macrophages during sterol import. Shown is the expression of ABCA9 mRNA by semiquantitative RT-PCR in human monocytes and macrophages. Lane 1: freshly obtained human monocytes. Lane 2: macrophages (Mac) maintained in culture in the presence of M-CSF for four days. Lane 3: macrophages as in lane 2 incubated with enzymatically degraded LDL (eLDL, $40 \mu \mathrm{g} / \mathrm{ml}$ ) for an additional $24 \mathrm{~h}$ (Mac + eLDL). Expression of the housekeeping reference gene GAPDH is shown in the bottom panel. The sizes of the diagnostic PCR products are 607 (ABCA9), 662 $(\mathrm{ABCA} 9 \Delta+55)$, and $280 \mathrm{bp}(\mathrm{GAPDH})$, respectively. RT-PCR was performed for 35 amplification cycles.

and lipid homeostasis. One finding of note in our experiments is the consistent co-regulation of the canonical ABCA9 transcript and the ABCA9 $\Delta+55$ splice variant which supports the notion that the abundance of both mRNAs is controlled by common regulatory mechanisms.

Among the members of the human ABC A-subfamily, sterol-dependent suppression of gene expression has also been reported for the recently identified transporter ABCA6, a close homolog of ABCA9 $[12,18]$. Presently, it is unclear whether the sterol-dependent inhibitory effect on the expression of both genes occurs at the transcriptional or post-transcriptional level. The identification and functional characterization of the ABCA6 and ABCA9 promoters will help elucidate the molecular mechanisms that underlie the cholesterol-responsive regulation of these structurally closely related $\mathrm{ABC}$ A-subclass transporters.

\section{ABCA9 mRNA tissue distribution}

The tissue-specific expression of ABCA9 was characterized using a multiple tissue RNA master blot containing mRNA from various human tissues. Dot blot analysis shows robust expression of human ABCA9 in a variety of tissues (Table 1). Highest expression was found in heart, brain, and fetal tissues (Table 1). The tissue expression pattern of ABCA9 is similar to that observed for the structurally related transporter ABCA6 [18]. In contrast to the latter, however, ABCA9 exhibits significantly higher expression levels in fetal tissues, in particular, in the fetal heart and kidney which suggests potential roles for this transporter during the development of these organs.
Table 1

RNA expression of ABCA9 and ABCA6 in various human tissues

\begin{tabular}{|c|c|c|}
\hline \multirow[t]{2}{*}{ Tissue } & \multicolumn{2}{|c|}{ Relative mRNA expression } \\
\hline & ABCA9 & ABCA6 \\
\hline Adrenal gland & $\bullet$ & \\
\hline Thymus & - & - \\
\hline Lung & $\bullet \bullet$ & $\bullet \bullet$ \\
\hline Heart & $\bullet \bullet \bullet \bullet$ & $\bullet \bullet \bullet$ \\
\hline Skeletal muscle & $\bullet$ & \\
\hline Spinal chord & $\bullet \bullet$ & $\bullet \bullet \bullet$ \\
\hline Corpus callosum & $\bullet \bullet \bullet$ & $\bullet \bullet \bullet$ \\
\hline Substantia nigra & $\bullet \bullet \bullet \bullet$ & $\bullet$ \\
\hline Spleen & $\bullet \bullet$ & $\bullet$ \\
\hline Lymphnode & $\bullet \bullet$ & $\bullet$ \\
\hline Pancreas & $\bullet$ & \\
\hline Placenta & $\bullet$ & \\
\hline Colon & $\bullet$ & $\bullet$ \\
\hline Prostate & $\bullet \bullet$ & $\bullet$ \\
\hline Testis & $\bullet$ & \\
\hline Ovary & $\bullet \bullet$ & $\bullet \bullet$ \\
\hline Uterus & $\bullet \bullet$ & $\bullet \bullet$ \\
\hline Mammary gland & $\bullet$ & \\
\hline Thyroid gland & $\bullet$ & $\bullet$ \\
\hline Kidney & $\bullet$ & $\bullet$ \\
\hline Liver & $\bullet \bullet \bullet \bullet$ & $\bullet \bullet \bullet$ \\
\hline Bone marrow & $\bullet$ & $\bullet$ \\
\hline Periph. leukocytes & $\bullet$ & $\bullet$ \\
\hline Fetal heart & $\bullet \bullet$ & \\
\hline Fetal kidney & $\bullet \bullet$ & \\
\hline Fetal liver & $\bullet$ & $\bullet$ \\
\hline Fetal spleen & $\bullet$ & \\
\hline Fetal thymus & $\bullet$ & \\
\hline Fetal lung & $\bullet$ & $\bullet$ \\
\hline
\end{tabular}

Gene expression levels for individual tissues were determined by dot blot analysis and quantitated densitometrically (Materials and methods). The signal densities were translated into a linear scale $(0-4)$ and are shown as dots.

\section{ABCA9 gene structure and exon/intron boundaries}

Amplification of the $5^{\prime}$ end of the ABCA9 cDNA using primers from regions of maximum homology between the cDNAs of ABCA8 and ABCA6 revealed that the ABCA9 transcription initiation region is located $>180 \mathrm{bp}$ upstream of the translation start site. This strongly suggests that the ABCA9 full-length coding region starts in the proximity of the $5^{\prime}$ end of exon 2 . Based on this information, ABCA9 candidate introns were amplified from human genomic DNA using long template PCR. Exon-specific primers, based on the comparison of the known gene structures of human ABCA6 [18], ABCA2 [17], and ABCA1 [27], respectively, were used which flanked putative ABCA9 exon/intron boundaries. The exon/intron organization of ABCA9 was assessed by direct sequencing of the respective PCR amplification products. The flanking regions of all intron spanning amplification products showed complete sequence identity with their respective cDNA counterparts. A total of 39 exons were thus identified (Table 2). The complete exon sequences of ABCA9 have been deposited with the 
Table 2

Exon-intron boundaries of the human ABCA9 gene

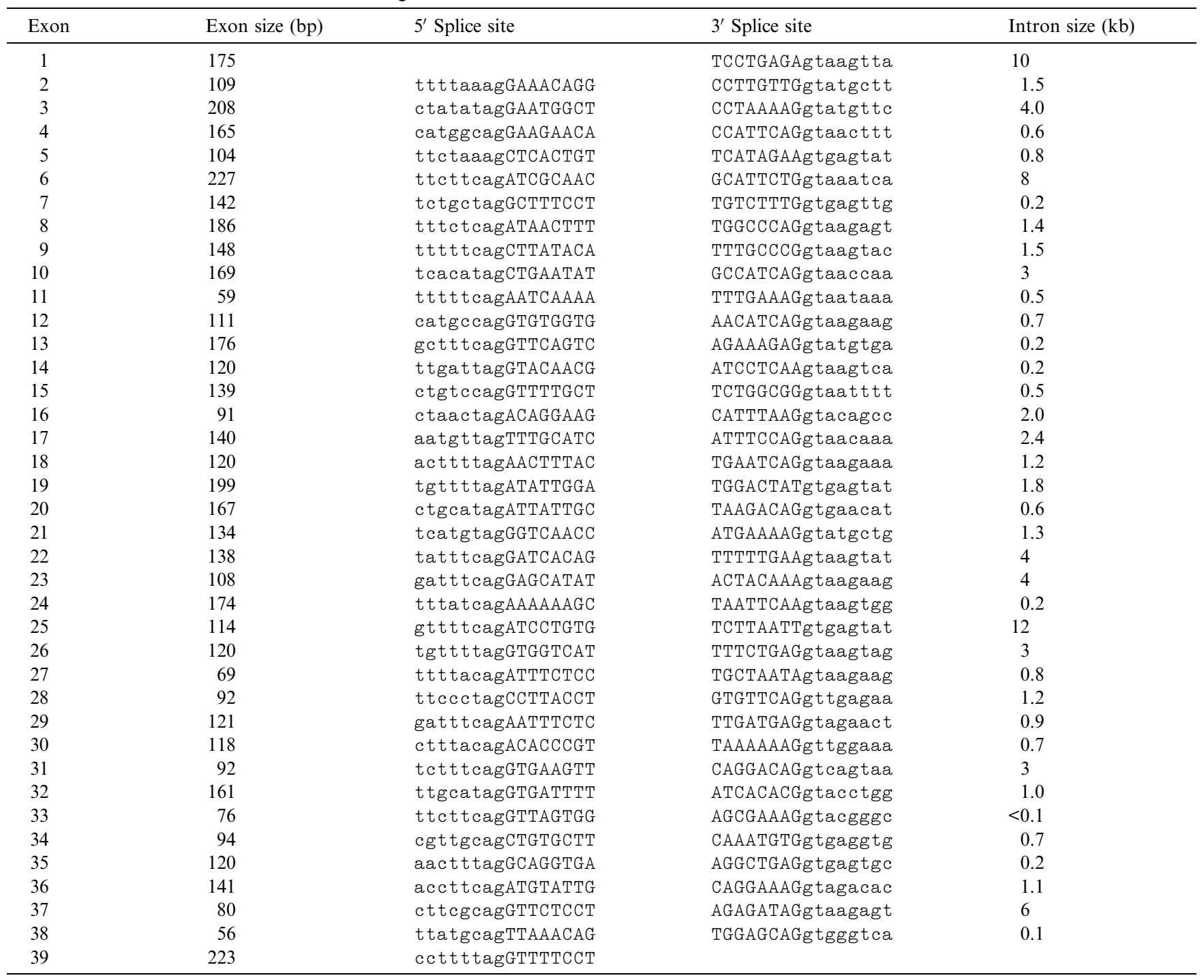

GenBank Database under Accession Nos. AF423308AF423346. Exons and most introns are relatively small in size comparable to those in the ABCA6 gene. Exon sizes range from 56 to $227 \mathrm{bp}$ and intron sizes are in the range from 73 to $11.8 \mathrm{~kb}$ (Table 2). The initial and terminal dinucleotides of all introns showed the GT-AG configuration diagnostic of splice junctions [28]. We found that the 39 exons of the ABCA9 span a genomic region of approximately $85 \mathrm{~kb}$ (Fig. 4). This structure is in accordance with the gene sizes reported for other human ABC A transporters (ABCA1, ABCA2, ABCR, ABCA6, and $A B C A 7)$ whose genomic regions range from 21 to $149 \mathrm{~kb}[17,18,27,29,30]$.

\section{Chromosomal assignment of the ABCA9 gene}

GenBank database analyses using the FASTA algorithm revealed $>99 \%$ identity of the whole assessed

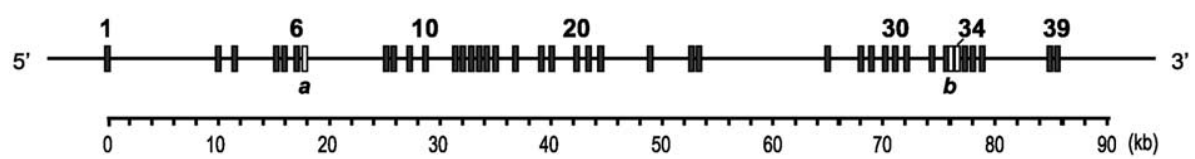

Chromosome $17 q 24.2$

Fig. 4. Structural organization of the ABCA9 gene on chromosome 17q24.2. Exons are numbered in $5^{\prime}$ to $3^{\prime}$ order and shown as black boxes. The alternative exon $6^{*}(\mathrm{a})$, the retained intron 33 (b), and the alternatively skipped exon 34 are represented by open boxes. A metric scale bar is indicated. 
ABCA9 gene sequence with a genomic sequence (Accession No. AC005922). Using the Genome Browser software (http://genome.ucsc.edu), we allocated this contig to the chromosomal region $17 \mathrm{q} 24.2-3$, strongly suggesting that the ABCA9 gene is localized at this chromosomal site. Interestingly, we could assign the loci for the ABCA8 and ABCA6 genes, the closest known homologs of ABCA9, to the same chromosomal region. This indicates that the ABCA9, ABCA8, and ABCA6 genes share a common region on chromosome $17 \mathrm{q} 24$. Importantly, detailed screening of this genomic region for coding sequences revealed that two additional genes encoding bona fide $\mathrm{ABC}$ transporters co-localize to this very genomic microenvironment (manuscript in preparation).

In conclusion, we have identified a novel member of the ABC A-subfamily of full-size transporters, designated $\mathrm{ABCA}$ 9, which represents the third member of the group of ABCA6-like ABC transporters. Moreover, we provide evidence for the existence of multiple mRNA variants potentially coding for truncated ABCA9 peptides in human macrophages. Our results demonstrating that the ABCA9 expression is induced during monocyte differentiation into macrophages and inhibited by cholesterol influx in human macrophages suggest that this novel transporter, like ABCA6, may serve functions in macrophage differentiation and lipid trafficking. Further work is required to determine the precise biological function of ABCA9 in transmembrane transport, in particular in the context with its close relatives ABCA8 and ABCA6. It will be particularly challenging to test whether and to which extent ABCA9 is implicated in fetal development.

\section{Acknowledgments}

We thank M. Häusler and N. Fenske for expert technical assistance. This study was funded by grants from the Deutsche Forschungsgemeinschaft (KA 1078/2-1 and AN 111/6-1, "Molekulare Grundlagen der Differenzierung und Aktivierung mononukleärer Phagozyten").

\section{References}

[1] C.F. Higgins, $\mathrm{ABC}$ transporters: from microorganisms to man, Annu. Rev. Cell Biol. 8 (1992) 67-113.

[2] M. Dean, Y. Hamon, G. Chimini, The human ATP-binding cassette ABC transporter superfamily, J. Lipid Res. 42 (2001) $1007-1017$.

[3] I. Klein, B. Sarkadi, A. Varadi, An inventory of the human ABC proteins, Biochim. Biophys. Acta 1461 (1999) 237-262.

[4] M. Dean, R. Allikmets, Evolution of ATP-binding cassette transporter genes, Curr. Opin. Genet. Dev. 5 (1995) 779-785.

[5] G. Schmitz, W.E. Kaminski, E. Orsó, ABC transporters in cellular lipid trafficking, Curr. Opin. Lipidol. 11 (2000) 493-501.

[6] G. Schmitz, W.E. Kaminski, ABC transporters and cholesterol metabolism, Front. Biosci. 6 (2001) D505-514.
[7] M. Bodzioch, E. Orsó, J. Klucken, T. Langmann, A. Böttcher, W. Diederich, W. Drobnik, S. Barlage, C. Büchler, M. PorschÖzcürümez, W.E. Kaminski, H.W. Hahmann, K. Oette, G. Rothe, C. Aslanidis, K.J. Lackner, G. Schmitz, The gene encoding ATP-binding cassette transporter 1 is mutated in Tangier disease, Nat. Genet. 22 (1999) 347-351.

[8] A. Brooks-Wilson, M. Marcil, S.M. Clee, L.H. Zhang, K. Roomp, M. van Dam, L. Yu, C. Brewer, J.A. Collins, H.O. Molhuizen, O. Loubser, B.F. Ouelette, K. Fichter, K.J. Ashbourne-Excoffon, C.W. Sensen, S. Scherer, S. Mott, M. Denis, D. Martindale, J. Frohlich, K. Morgan, B. Koop, S. Pimstone, J.J. Kastelein, J. Genest, M.R. Hayden, Mutations in ABC1 in Tangier disease and familial high-density lipoprotein deficiency, Nat. Genet. 22 (1999) 336-345.

[9] S. Rust, M. Rosier, H. Funke, J. Real, Z. Amoura, J.C. Piette, J.F. Deleuze, H.B. Brewer, N. Duverger, P. Denefle, G. Assmann, Tangier disease is caused by mutations in the gene encoding ATP-binding cassette transporter 1, Nat. Genet. 22 (1999) 352-355.

[10] E. Orsó, C. Broccardo, W.E. Kaminski, A. Böttcher, G. Liebisch, W. Drobnik, A. Götz, O. Chambenoit, W. Diederich, T. Langmann, T. Spruss, M.-F. Luciani, G. Rothe, K.J. Lackner, G. Chimini, G. Schmitz, Transport of lipids from Golgi to plasma membrane is defective in Tangier disease patients and $\mathrm{ABCl}$ deficient mice, Nat. Genet. 24 (2000) 192-196.

[11] M. van Eck, I.S.T. Bos, W.E. Kaminski, E. Orsó, G. Rothe, J. Twisk, A. Böttcher, E.S. van Amersfoort, T.A. ChristiansenWeber, W.-P. Fung-Leung, T.J.C. van Berkel, G. Schmitz, Leukocyte ABCA1 controls susceptibility to atherosclerosis and macrophage recruitment into tissues, Proc. Natl. Acad. Sci. USA 99 (2002) 6298-6303.

[12] J. Klucken, C. Büchler, E. Orsó, W.E. Kaminski, M. PorschÖzcürümez, G. Liebisch, M. Kapinsky, W. Diederich, W. Drobnik, M. Dean, R. Allikmets, G. Schmitz, ABCG1 (ABC8), the human homolog of the Drosophila white gene, is a regulator of macrophage cholesterol and phospholipid transport, Proc. Natl. Acad. Sci. USA 97 (2000) 817-822.

[13] A.K. Bhattacharyya, W.E. Connor, $\beta$-Sitosterolemia and xanthomatosis. A newly described lipid storage disease in two sisters, J. Clin. Invest. 53 (1974) 1033-1043.

[14] K.E. Berge, H. Tian, G.A. Graf, L. Yu, N.V. Grishin, J. Schultz, P. Kwiterovich, B. Shan, R. Barnes, H.H. Hobbs, Accumulation of dietary cholesterol in sitosterolemia caused by mutations in adjacent ABC transporters, Science 290 (2000) 1771-1775.

[15] M.H. Lee, K. Lu, S. Hazard, H. Yu, S. Shulenin, H. Hidaka, H. Kojima, R. Allikmets, N. Sakuma, R. Pegoraro, A.K. Srivastava, G. Salen, M. Dean, S.B. Patel, Identification of a gene, ABCG5, important in the regulation of dietary cholesterol absorption, Nat. Genet. 27 (2001) 79-83.

[16] W.E. Kaminski, E. Orsó, W. Diederich, J. Klucken, W. Drobnik, G. Schmitz, Identification of a novel human sterol-sensitive ATPbinding cassette transporter (ABCA7), Biochem. Biophys. Res. Commun. 273 (2000) 532-538.

[17] W.E. Kaminski, A. Piehler, K. Püllmann, M. Porsch-Ozcurumez, C. Duong, G. Maa Bared, C. Büchler, G. Schmitz, Complete coding sequence, promoter region, and genomic structure of the human ABCA2 gene and evidence for sterol-dependent regulation in macrophages, Biochem. Biophys. Res. Commun. 281 (2001) 249-258.

[18] W.E. Kaminski, J.J. Wenzel, A. Piehler, T. Langmann, G. Schmitz, ABCA6, a novel a subclass ABC transporter, Biochem. Biophys. Res. Commun. 285 (2001) 1295-1301.

[19] M.-F. Luciani, F. Denizot, S. Savary, M.G. Mattei, G. Chimini, Cloning of two novel $\mathrm{ABC}$ transporters mapping on human chromosome 9, Genomics 21 (1994) 150-159.

[20] T. Langmann, J. Klucken, M. Reil, G. Liebisch, M.-F. Luciani, G. Chimini, W.E. Kaminski, G. Schmitz, Molecular cloning of the human ATP-binding cassette transporter 1 (hABC1): evidence for 
sterol-dependent regulation in macrophages, Biochem. Biophys. Res. Commun. 257 (1999) 29-33.

[21] S. Bhakdi, M. Torzewski, M. Klouche, M. Hemmes, Complement and atherogenesis: binding of CRP to degraded, nonoxidized LDL enhances complement activation, Arterioscler. Thromb. Vasc. Biol. 19 (1999) 2348-2354.

[22] J.M. Chirgwin, A.E. Przybyla, R.J. MacDonald, W.J. Rutter, Isolation of biologically active ribonucleic acid from sources enriched in ribonuclease, Biochemistry 18 (1979) 52945299.

[23] T. Langmann, A. Becker, C. Aslanidis, F. Notka, H. Ullrich, H. Schwer, G. Schmitz, Structural organization and characterization of the promoter region of a human carboxylesterase gene, Biochim. Biophys. Acta 1350 (1997) 65-74.

[24] R. Allikmets, B. Gerrard, A. Hutchinson, M. Dean, Characterization of the human $\mathrm{ABC}$ superfamily: isolation and mapping of 21 new genes using the expressed sequence tags database, Hum. Mol. Genet. 5 (1996) 1649-1655.

[25] I. Arnould, L.M. Schriml, C. Prades, M. LachtermacherTriunfol, T. Schneider, C. Maintoux, C. Lemoine, D. Debono, C. Devaud, L. Naudin, S. Bauche, M. Annat, T. Annilo, R. Allikmets, B. Gold, P. Denefle, M. Rosier, M. Dean, Identifying and characterizing a five-gene cluster of ATP-binding cassette transporters mapping to human chromosome 17q24: a new subgroup within the ABCA subfamily, GeneScreen 1 (2001) $157-164$.
[26] R. Allikmets, N. Singh, H. Sun, N.F. Shroyer, A. Hutchinson, A. Chidambaram, B. Gerrard, L. Baird, D. Stauffer, A. Peiffer, A. Rattner, P. Smallwood, Y. Li, K.L. Anderson, R.A. Lewis, J. Nathans, M. Leppert, M. Dean, J.R. Lupski, A photoreceptor cell-specific ATP-binding transporter gene (ABCR) is mutated in recessive Stargardt macular dystrophy, Nat. Genet. 15 (1997) 236 246.

[27] A.T. Remaley, S. Rust, M. Rosier, C. Knapper, L. Naudin, C. Broccardo, K.M. Peterson, C. Koch, I. Arnould, C. Prades, N. Duverger, H. Funke, G. Assman, M. Dinger, M. Dean, G. Chimini, S. Santamarina-Fojo, D.S. Fredrickson, P. Denefle, H.B Brewer Jr., Human ATP-binding cassette transporter 1 (ABC1): genomic organization and identification of the genetic defect in the original Tangier disease kindred, Proc. Natl. Acad. Sci. USA 96 (1999) 12685-12690.

[28] R. Breathnach, P. Chambon, Organization and expression of eucaryotic split genes coding for proteins, Annu. Rev. Biochem. 50 (1981) 349-383.

[29] R. Allikmets, W.W. Wasserman, A. Hutchinson, P. Smallwood, J. Nathans, P.K. Rogan, T.D. Schneider, M. Dean, Organization of the ABCR gene: analysis of promoter and splice junction sequences, Gene 215 (1998) 111-122.

[30] W.E. Kaminski, A. Piehler, G. Schmitz, Genomic organization of the human cholesterol-responsive $\mathrm{ABC}$ transporter ABCA7: tandem linkage with the minor histocompatibility antigen HA-1 gene, Biochem. Biophys. Res. Commun. 278 (2000) 782-789. 